\title{
Optical force decoration of 3D microstructures with plasmonic particles
}

\author{
M. G. Donato ${ }^{1, *}$, V. P. Rajamanickam ${ }^{2}$, A. Foti ${ }^{1, \dagger}$, P. G. Gucciardi ${ }^{1}$, C. Liberale ${ }^{2, *}$, and O. M. \\ MARAGó ${ }^{1, *}$ \\ ${ }^{1}$ CNR-IPCF, Istituto per i Processi Chimico-Fisici, Viale F. Stagno D'Alcontres, 37, I-98158 Messina, Italy \\ ${ }^{2}$ Vibrational Imaging Laboratory, BESE and CEMSE Divisions, King Abdullah University of Science and Technology (KAUST), Thuwal 23955-6900, Saudi \\ Arabia \\ *Corresponding authors: maria.donato@cnr.it,carlo.liberale@kaust.edu.sa, onofrio.marago@cnr.it \\ ${ }^{+}$Present address: LPICM, Ecole Polytechnique, CNRS, 91128 Palaiseau France
}

Optical forces are used to push and aggregate gold nanorods onto several substrates creating SERS active hot-spots for Raman-based identification of proteins. By monitoring the increase of the protein SERS signal, we observe different aggregation times for different curvature of the substrates. The slower aggregation dynamics on curved surfaces is justified by a simple geometrical model. In particular, this technique is used to decorate three-dimensional microstructures and to quickly realize hybrid micro/nanosensors for highly sensitive detection of biological material directly in liquid environment. (c) 2018 Optical Society of America

OCIS codes: (350.4855) Optical tweezers or optical manipulation;(240.6695) Surface-enhanced Raman scattering; (220.4610) Optical fabrication.

\section{http://dx.doi.org/10.1364/ao.XX.XXXXXX}

Optical trapping and optical manipulation of particles is a consequence of the conservation of electromagnetic momentum in light-matter interaction [1,2]. Generally, when a small particle interacts with a laser beam, it is pushed in the direction of light propagation by the radiation pressure $[3,4]$. If the laser beam is focused by a high numerical aperture objective, the strong intensity gradient in the laser spot causes an additional optical gradient force, directed towards the laser focus [5]. Optical trapping is observed when this gradient force is larger than radiation pressure, creating the so-called optical tweezers [1,5]. Optical tweezers have been recently used to confine and study nanomaterials [6]. Plasmonic [7-12], hybrid dielectric-metal nanoparticles [13, 14], spherical and non-spherical nanoparticles [15-18] have been successfully trapped and manipulated. Recently, optical pushing has been also used to realize all-optical force stamping of substrates with plasmonic nanoparticles [9, 19-21], for the controlled deposition of layered nanosheets [22] and even to form aggregates that act as sensors for the high-sensitivity detection of molecular species directly in liquid environment $[23,24]$. In this context, it has been shown that surface-enhanced Raman scattering [12] (SERS-)active aggregates can be created on glass substrates by optical manipulation of $\mathrm{Au}$ nanorods (AuNRs) [23] in a liquid environment containing biomolecules. In fact, due to their very large extinction cross-sections in proximity of their opto-plasmonic peak, they are pushed by radiation pressure towards the sample chamber glass walls where they aggregate and form hot-spots in which the Raman spectrum of a diluted biomolecule, such as Bovine Serum Albumin (BSA), can be strongly enhanced [23]. With this technique, the Raman limit of detection of BSA in water can be lowered from $10^{-3} \mathrm{M}$ to $5 \cdot 10^{-8} \mathrm{M}$ [24]. It is interesting to assess if the pushing pro-

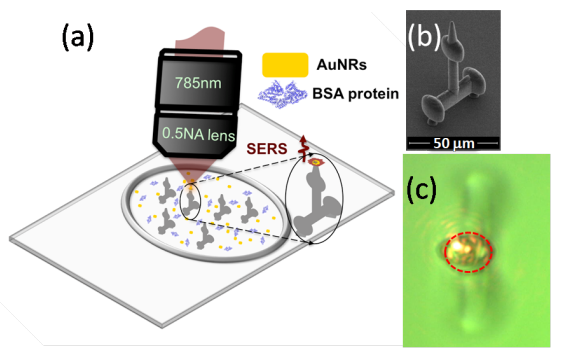

Fig. 1. (a) Sketch of the experimental set-up. AuNRs dispersed in water are mixed and stabilized with BSA protein molecules [23]. The sample is placed in a micro-cell where TPP microstructures (tripods) are present. Upon illumination with a focused laser beam, radiation pressure pushes the BSAAuNRs complexes within the focal spot creating SERS-active aggregates and controlled decoration of the tripod tip in few minutes. The aggregation dynamics is monitored by detecting the BSA SERS spectrum at different times. (b) SEM image of one of the tripods studied in this work. (c) Microscope image of a tripod tip, with the laser beam focused on it (red dashed ring). Color online.

cess of AuNRs is valid also on curved substrates other than flat glass. In this case, optical forces could be used to provide fast decoration of three dimensional (3D) micro- and nanostructures such as those obtained with direct laser writing by two-photon photopolymerization (TPP) [25]. This can be considered as a high-resolution $3 \mathrm{D}$ printing technique with sub-micron reso- 
lution, and is based on the 3D localized polymerization of a suitable resin through two-photon absorption of a tightly focused laser beam. Thanks to the capability to fabricate arbitrary shape 3D micro/nano-structures, TPP has found application in very different areas such as photonics, microfluidics, electronics and biology [26-33]. In contrast to other 3D SERS substrate fabrication techniques [34-37], the possibility to deposit metal particles on only specific areas of 3D structures fabricated by TPP is a highly desirable feature that has been rarely explored [33], which could potentially open new opportunities, e.g. for SERS sensing or thermoplasmonics [12].

In this work, the aggregation process of AuNRs driven by optical forces $[23,24]$ is tested on three substrates: ordinary glass microscope slides, $5 \mu \mathrm{m}$ diameter polystyrene beads, and the submicron tip of a complex polymer structure, which we call "optical tripod" (see Fig. 1 b) obtained by TPP [38]. Sensitive Raman fingerprinting of a biomolecule, enhanced by the aggregated AuNRs, is obtained on the different substrates, without any type of preparation or functionalization of the surfaces.
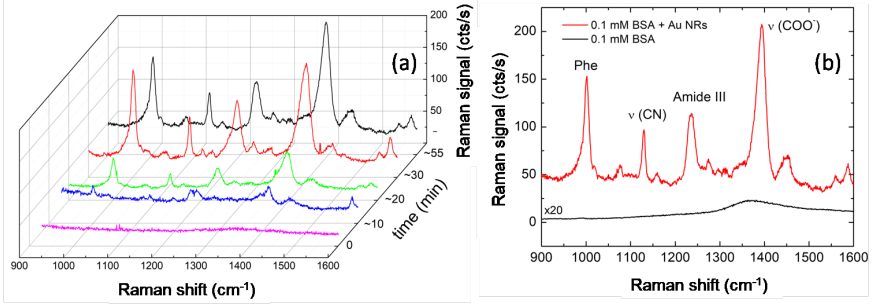

Fig. 2. (a) Time evolution of SERS spectra of BSA obtained by pushing AuNRs on a tripod tip. The tripods were immersed in a 4:1 $0.1 \mathrm{mM}$ BSA-AuNRCs solution. The laser beam, with $\lambda=785 \mathrm{~nm}$, is focused by a 0.5 NA LWD objective that delivers $\sim 3 \mathrm{~mW}$ at the sample. The peaks in the red (35 $\mathrm{min})$ and black (55 min) spectra have similar heights showing the saturation of the decoration process. (b) Raman spectrum of BSA 0.1 $\mathrm{mM}$ in PBS (black curve) and of a 4:1 mixture of the same BSA solution and AuNRs (red curve) obtained by optical pushing AuNRs on a tripod tip. The black spectrum shows only the background signal from the underlying glass slide. Instead, the red spectrum shows typical peaks connected with the BSA molecules. Color online.

Fabrication of 3D microstructures has been performed by using a commercial direct laser writer system based on TPP (Photonic Professional GT, Nanoscribe Gmbh) and the proprietary IP-L 780 photoresist (Nanoscribe Gmbh). Size of the tripod is $25 \mu \mathrm{m} \times 10 \mu \mathrm{m} \times 40 \mu \mathrm{m}$ with top tip radius of $140 \mathrm{~nm}$. Fabrication time for each tripod structure is about 3 minutes and the unexposed resist is removed with propylene glycol methyl ether acetate (PGMEA, Micro resist technology GMBH) for few minutes, isopropyl alcohol (IPA, Sigma Aldrich) for few seconds and finally air-dried at ambient condition. Commercial gold nanorods, with $35 \mathrm{~nm}$ diameter and $90 \mathrm{~nm}$ length, have been purchased from Nanopartz and used as received (SEM morphology is available at www.nanopartz.com). Their concentration in deionized (DI) water is $0.05 \mathrm{mg} / \mathrm{ml}$, equivalent to ca. $3 \times 10^{7}$ rods $/ \mu \mathrm{L}$. The solution contains $<0.1 \%$ ascorbic acid and $<0.1 \%$ cetyltrimethylammonium bromide (CTAB) surfactant to prevent spontaneous re-aggregation. AuNRs are characterized by a short axis plasmon resonance at $527 \mathrm{~nm}$ and a long axis plasmon resonance at $687 \mathrm{~nm}$ [23]. A $10^{-4} \mathrm{M}$ Bovine Serum
Albumin (BSA, Sigma Aldrich, A6003) in phosphate buffer (PB, $200 \mathrm{mM}$ ) aqueous solution has been added to the AuNRs water dispersion at 4:1 BSA:AuNRs volume fraction. Upon mixing, BSA-AuNRs complexes (BSA-AuNRCs) are formed in which BSA molecules substitute the CTAB layer around the AuNRs [23]. Under optical pushing, the complexes are driven towards the substrate, where they adhere [22-24] thanks to the BSA layer [39]. The sample chamber has been realized with a microscope slide, a $\sim 120 \mu \mathrm{m}$ thick adhesive spacer and a No. 1.5 coverslip. Approximately $10 \mu \mathrm{L}$ of BSA-AuNRCs have been loaded in the sample chamber. Pushing measurements have been carried out in a Horiba Jobyn-Yvon HR800 setup at $785 \mathrm{~nm}$ exciting wavelength. This wavelength is well suited for optimizing both the pushing process and SERS detection since it lies close to the plasmonic peak of the individual AuNRs, maximizing the scattering force, and within the broader infrared plasmonic response of the aggregated AuNRs, maximizing SERS [23]. The power at the exit pupil of a 50X magnification long working distance objective (NA=0.5) was about $3 \mathrm{~mW}$. To push BSA-AuNRCs onto commercial polystyrene beads, an aqueous dispersion of these particles has been drop cast on the glass slide. After evaporation of water, the sample chamber has been built as indicated above. In the case of pushing onto the tip of the tripods, these structures have been directly fabricated on the glass slide, on which the sample chamber has been built. The decoration process has been carried out by positioning the laser spot just where we wished the aggregate to form. The BSA-AuNRCs entering the laser beam are pushed towards the glass, the latex bead, or the tripod tip and adhere to it. During the aggregation process, Raman spectra have been collected every 15 seconds. Optical pushing and consequent aggregation of BSA-AuNRCs has been monitored by means of successive acquisitions of Raman spectra when focusing on the tripod tip (Fig. 2a). At the beginning of the pushing process (magenta spectrum), we do not detect any Raman feature from the BSA molecules or the tip material. However, after approximately 10 minutes (blue spectrum), some features appear whose amplitude increase with time. After approximately 35 minutes (red spectrum) the Raman signal reaches a saturation value. Once saturated, the Raman signal on the tripod is stable over time, i.e., the peaks in the spectra at longer time have similar heights (as for the red, $35 \mathrm{~min}$, and black, 55 min, spectra) and no further substantial growth is observed. In Fig.2b, the Raman spectrum obtained at saturation (red curve) is compared with that obtained in a $10^{-4} \mathrm{M}$ BSA water solution (black curve). Peaks connected to phenylalanine ring breathing (at $\sim 1000 \mathrm{~cm}^{-1}$ ), to $\mathrm{CN}$ and $\mathrm{COO}^{-}$stretching vibrations (at $\sim 1130 \mathrm{~cm}^{-1}$ and $\sim 1396 \mathrm{~cm}^{-1}$, respectively) and to the Amide III band (at $\sim 1238 \mathrm{~cm}^{-1}$ ) are easily recognized [23]. On the contrary, at the same protein dilution and in absence of AuNRs, no BSA Raman features are observed. Thus, it is clear that the aggregation of AuNRs induced by optical forces is effective in creating a SERS substrate for BSA detection. Furthermore, the BSA-AuNRCs solution is stable with time and without optical pushing no Raman signal from the proteins is observed when probing the surfaces even after several hours. Thus, a simple diffusion of the BSA-AuNRs complexes towards the substrate is not a plausible mechanism for the observed enhancement of the Raman spectrum with time.

The aggregation process on different substrates follows a similar evolution towards a saturation of the Raman signal, but with different time characteristics. In Fig. 3, the aggregation process on a flat glass slide (a), a $5 \mu \mathrm{m}$ diameter polystyrene bead (b), and a tripod tip (c) are compared. The data points 


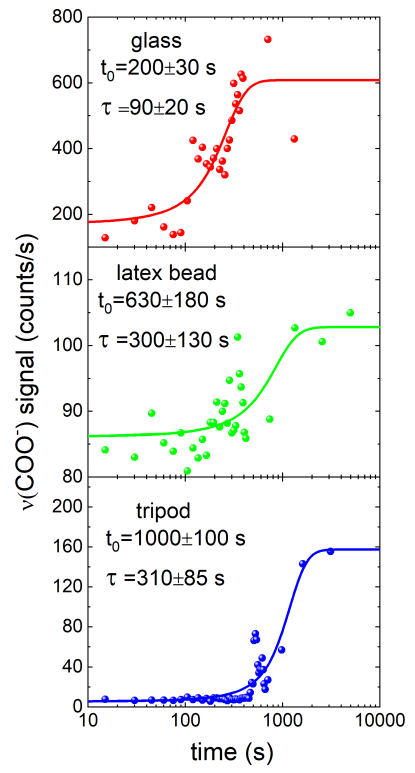

Fig. 3. Growth curves as a function of time of $v\left(\mathrm{COO}^{-}\right)$SERS peak on different substrates. Solid lines are the fit to the data with a Boltzmann growth equation. The aggregation time threshold, $t_{0}$, and the aggregation rate, $\tau$, are also indicated. The sum $t_{0}+\tau$ represents the time needed for the decoration process to reach saturation. The difference in the curves background is related to the different glass fluorescence detected at different height from the microscope slide. Color online.

correspond to the amplitude of the Raman $v\left(\mathrm{COO}^{-}\right)$peak at $\sim 1396 \mathrm{~cm}^{-1}$. The solid lines are the fit to the data with a Boltzmann growth curve [40]:

$$
y(t)=\frac{A_{1}-A_{2}}{1+e^{\left(t-t_{0}\right) / \tau}}+A_{2}
$$

where $t_{0}$ is the time threshold at which the signal reaches $50 \%$ of the initial plus final $A_{1}$ and $A_{2}$ values and $\tau$ is connected to the slope of the curve at $t_{0}$, namely, $y^{\prime}\left(t_{0}\right)=\frac{A_{2}-A_{1}}{4 \tau}$. Thus, the sum $t_{0}+\tau$ represents the time needed for the decoration process to saturate at an intensity value $A_{2}$. The temporal parameters, $t_{0}$ and $\tau$, are robust and reproducible in the same experimental conditions, while the absolute saturation values, $A_{2}$, are more prone to variation up to a factor of 3 [24]. Thus, we mainly focus our analysis on growth times. The fit of the data shows that the aggregation process requires more time to start, and that, consequently, the SERS signal is detected later, passing from the glass substrate to the latex bead and finally to the tripod tip. Correspondingly, $\tau$ increases (see the values in Fig.3), meaning that on the latex bead and the tripod tip the aggregation is slower and more time is required to saturate the Raman signal. Similar temporal evolutions are obtained following the growth of different Raman peaks, such as the phenylalanine ring breathing at $1000 \mathrm{~cm}^{-1}$ or the $v(\mathrm{CN})$ peak at $1130 \mathrm{~cm}^{-1}$. By averaging the $t_{0}$ and $\tau$ values obtained from these three peaks, we obtain the data reported on Table 1 .

Simple geometrical considerations may be introduced to explain the slower dynamics of aggregation process on curved surfaces when compared to a flat substrate. First, the interaction region of the laser Gaussian beam can be safely limited to the focal region that can be approximated by considering a waist $w_{0}$ as the diffraction limit given by the Abbe criterion, in our case a)

b)

c)
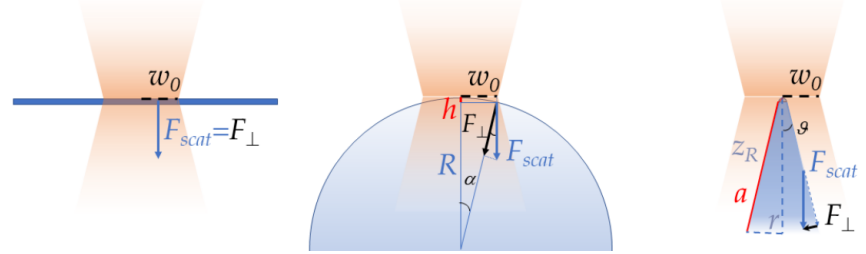

Fig. 4. Sketch of the pushing process on the different substrates: a) glass slide, b) $5 \mu \mathrm{m}$ bead, c) tripod tip. $w_{0}$ is the waist of the Gaussian beam, $F_{\text {scat }}$ is the scattering force, while $F_{\perp}$ is its component normal to the substrate. In b) $R$ is the bead radius, $\alpha$ the aperture angle, $h$ the height of the spherical cap intercepted by the laser spot. In c) $z_{R}$ is the Rayleigh range of the beam, that is also the height of the interaction region, $\vartheta$ is the cone aperture angle, $r$ the radius of the cone, $a$ the slant height. Only the portion of the tripod tip in the interaction region, with height equal to $z_{R}$, has been drawn. The whole tip has $6 \mu \mathrm{m}$ height. Color online.

\begin{tabular}{cccc} 
& glass & $5 \mu m$ bead & tripod \\
\hline$<t_{0}>$ (s) & $160 \pm 40$ & $470 \pm 90$ & $1120 \pm 90$ \\
$<\tau>$ (s) & $100 \pm 30$ & $200 \pm 70$ & $320 \pm 60$ \\
\hline
\end{tabular}

Table 1. Time parameters obtained by averaging the values from the growth curve fitting (Eq. 1) of the three main Raman peaks (at $1000 \mathrm{~cm}^{-1}, 1130 \mathrm{~cm}^{-1}$, and $1396 \mathrm{~cm}^{-1}$ ).

$w_{0} \approx 600 \mathrm{~nm}$, and corresponding Rayleigh range, $z_{R} \approx 1.9 \mu \mathrm{m}$. Within this interaction region we can consider the laser beam to have approximately a flat phase and the optical scattering force, $F_{\text {scat }}$, to be directed as the propagation axis. Moreover, we assume that the probability for a BSA-AuNRC entering the focal spot to stick to the substrate is proportional to the component, $F_{\perp}$, of the scattering force perpendicular to the surface. For a flat glass slide (Fig. 4 a), the scattering force is normal to the surface, hence $F_{\text {scat }}=F_{\perp}$. If we assume a unitary probability that a BSA-AuNRC entering the focal spot is attached to the slide, all the BSA-AuNRCs entering the spot will stick to the microscope slide and will contribute to the SERS signal of the BSA. Moreover, the Raman signal saturation value, described by the parameter $A_{2}$, and consequently both the time parameters, $t_{0}$ and $\tau$, are connected to the illuminated area of the surface, i.e, the larger the area, the longer time is needed to fill it with pushed BSA-AuNRCs and to saturate the Raman signal. The illuminated area on the glass slide corresponds to $A_{\text {flat }}=\pi w_{0}^{2} \approx 1.13 \mu \mathrm{m}^{2}$. Instead the illuminated area on curved surfaces will be different. In fact, on the $5 \mu \mathrm{m}$ diameter bead (Fig. $4 \mathrm{~b}$ ), the illuminated region has a maximum aperture angle $\alpha=\operatorname{asin}\left(w_{0} / R\right) \approx 13.9$ degrees, yielding a perpendicular force component $F_{\perp}=\cos \alpha \cdot F_{\text {scat }}=\sqrt{1-\left(w_{0} / R\right)^{2}} \approx 0.97 F_{\text {scat }}$ and an illuminated spherical cap $A_{\text {cap }}=2 \pi R h \approx 1.18 \mu \mathrm{m}^{2}$, with height $h=R(1-\cos \alpha)$. Thus, the component of the pushing force normal to the surface slightly decreases and the illuminated area weakly increases. This justifies a slight increase of both the time $t_{0}$ required to detect a Raman signal and of the time $\tau$ needed to increase the signal itself. A more striking effect is expected on the tripod tip, due to its sharp geometry. The tip has a rounded edge with a $140 \mathrm{~nm}$ curvature ra- 
dius and an aperture angle $\vartheta$ of approximately 13 degrees. The height of the tip is about $6 \mu \mathrm{m}$, well beyond the beam Rayleigh range. As the curvature radius of the edge is more than four times smaller than the beam waist, in a first approximation we can consider the tip as a sharp cone. In this case (see Fig.4 c), $F_{\perp}=\sin \vartheta F_{\text {scat }} \approx 0.23 F_{\text {scat }}$ and the illuminated area is $A_{\text {cone }}=\pi r a=\pi z_{R}^{2} \sin \vartheta / \cos ^{2} \vartheta \approx 2.7 \mu m^{2}, r$ and $a$ being the cone radius and the slant height, respectively. Thus, the probability that a BSA-AuNRC entering the beam spot is attached to the tip is lowered approximately 4 times with respect to a flat surface. Furthermore, the illuminated area is more than doubled, justifying heuristically the pronounced increase in both $t_{0}$ and $\tau$. It is also worth noting that surface properties may play a role in the sticking of the BSA-AuNRCs since protein adsorption phenomena are connected to the surface hydrophobicity and wettability [41]. However, although made of different materials, the three substrates have similar characteristics as they are inert, unfunctionalized, with similar smoothness, and wetting stability also related to the BSA stabilized dispersion. Moreover, BSA is known for its great adhesion properties [39], thus similar sticking of our BSA-AuNRCs are reasonably expected on all three substrates studied in this work. Note that our model is general and can be easily applied also to those methodologies based on optical force stamping [9, 19-21].

In conclusion, optical pushing of BSA-AuNRCs has been used to create SERS active hot-spots onto several 3D microstructures without any functionalization of the substrate. On these sites, the Raman spectrum of a biomolecule has been remarkably enhanced by the optical force aggregation process. A model has been proposed that, despite its simplicity, grasps the essential role of the surface shape on the decoration process. This gives a reasonable basis for the understanding of the time evolution of the protein SERS spectra obtained by optically pushing the AuNRs on curved substrates. Optical pushing can be used, in principle, with any kind of nanostructures, such as nanoparticles with a plasmonic response in a wide spectral region. Our results show that it can be used to rapidly (few minutes) and easily decorate complex microstructures with nanoparticles and to realize complex SERS sensors or thermoplasmonics probes having different shapes and functionalities directly in a liquid environment.

\section{REFERENCES}

1. P. H. Jones, O. M. Maragò, and G. Volpe, Optical tweezers: Principles and applications (Cambridge University Press, Cambridge, 2015).

2. P. Polimeno, A. Magazzù, M. A. latì, F. Patti, R. Saija, C. Degli Esposti Boschi, M. G. Donato, P. G. Gucciardi, P. H. Jones, G. Volpe, and O. M. Maragò, J. Quant. Spectrosc. \& Radiat. Transf. 218, 131 (2018).

3. A. Ashkin, Phys. Rev. Lett. 24, 156 (1970).

4. P. C. Chaumet and M. Nieto-Vesperinas, Opt. Lett. 25, 1065 (2000).

5. A. Ashkin, J. Dziedzic, J. Bjorkholm, and S. Chu, Opt. Lett. 11, 288 (1986).

6. O. M. Maragò, P. H. Jones, P. G. Gucciardi, G. Volpe, and A. C. Ferrari, Nat. Nanotechnol. 8, 807 (2013).

7. K. Svoboda and S. M. Block, Opt. Lett. 19, 930 (1994).

8. E. Messina, E. Cavallaro, A. Cacciola, M. A. latì, P. G. Gucciardi, F. Borghese, P. Denti, R. Saija, G. Compagnini, M. Meneghetti, V. Amendola, and O. M. Maragò, ACS Nano 5, 905 (2011).

9. A. S. Urban, S. Carretero-Palacios, A. A. Lutich, T. Lohmüller, J. Feldmann, and F. Jäckel, Nanoscale 6, 4458 (2014).

10. O. Brzobohatỳ, M. Šiler, J. Trojek, L. Chvátal, V. Karásek, A. Paták, Z. Pokorná, F. Mika, and P. Zemánek, Sci. Reports 5, 8106 (2015).

11. O. Brzobohatỳ, M. Šiler, J. Trojek, L. Chvátal, V. Karásek, and P. Zemánek, Opt. express 23, 8179 (2015).
12. V. Amendola, R. Pilot, M. Frasconi, O. M. Marago, and M. A. lati, J. Physics: Condens. Matter 29, 203002 (2017).

13. D. Spadaro, M. A. latì, M. G. Donato, P. G. Gucciardi, R. Saija, A. R. Cherlakola, S. Scaramuzza, V. Amendola, and O. M. Maragò, RSC Adv. 5, 93139 (2015).

14. D. Spadaro, M. A. latì, J. Perez-Pineiro, C. Vázquez-Vázquez, M. A. Correa-Duarte, M. G. Donato, P. G. Gucciardi, R. Saija, G. Strangi, and O. M. Marago, J. Phys. Chem. C pp. 691-700 (2017).

15. M. G. Donato, S. Vasi, R. Sayed, P. H. Jones, F. Bonaccorso, A. C. Ferrari, P. G. Gucciardi, and O. M. Maragò, Opt. Lett. 37, 3381 (2012).

16. S. Skelton, M. Sergides, R. Patel, E. Karczewska, O. Maragó, and P. Jones, J. Quant. Spectrosc. Radiat. Transf. 113, 2512 (2012).

17. E. Messina, M. G. Donato, M. Zimbone, R. Saija, M. A. latì, L. Calcagno, M. E. Fragala, G. Compagnini, C. D’Andrea, A. Foti, P. G. Gucciardi, and O. M. Maragò, Opt. Express 23, 8720 (2015).

18. A. Irrera, A. Magazzu', P. Artoni, S. H. Simpson, S. Hanna, P. H. Jones, F. Priolo, P. G. Gucciardi, and O. M. Marago, Nano Lett. 16, 4181 (2016).

19. M. J. Guffey and N. F. Scherer, Nano Lett. 10, 4302 (2010).

20. S. Nedev, A. S. Urban, A. A. Lutich, and J. Feldmann, Nano Lett. 11, 5066 (2011).

21. J. Gargiulo, I. L. Violi, S. Cerrota, L. Chvatal, E. Cortes, E. M. Perassi, F. Diaz, P. Zemanek, and F. D. Stefani, ACS nano 11, 9678 (2017).

22. M. G. Donato, E. Messina, A. Foti, T. Smart, P. Jones, M. A. latì, R. Saija, P. G. Gucciardi, and O. M. Maragò, Nanoscale 10, 1245 (2018).

23. B. Fazio, C. D’Andrea, A. Foti, E. Messina, A. Irrera, M. G. Donato, V. Villari, N. Micali, O. M. Maragò, and P. G. Gucciardi, Sci. Rep. 6 , 26952 (2016).

24. A. Foti, C. D'Andrea, V. Villari, N. Micali, M. G. Donato, B. Fazio, O. M. Maragò, R. Gillibert, M. Lamy de la Chapelle, and P. G. Gucciardi, Materials. 11, 440 (2018).

25. H.-B. Sun and S. Kawata, Adv. Polym. Sci. 170, 169 (2004).

26. C. Liberale, G. Cojoc, P. Candeloro, G. Das, F. Gentile, F. De Angelis, and E. Di Fabrizio, IEEE Photonics Technol. Lett. 22, 474 (2010).

27. C. Liberale, G. Cojoc, F. Bragheri, P. Minzioni, G. Perozziello, R. La Rocca, L. Ferrara, V. Rajamanickam, E. Di Fabrizio, and I. Cristiani, Sci. Reports 3, 1258 (2013).

28. G. Nelson, R. Kirian, U. Weierstall, N. Zatsepin, T. Faragó, T. Baumbach, F. Wilde, F. Niesler, B. Zimmer, I. Ishigami, M. Hikita, S. Bajt, S.-R. Yeh, D. Rousseau, H. Chapman, J. Spence, and M. Heymann, Opt. Express 24, 11515 (2016).

29. S. Hengsbach and A. D. Lantada, Biomed. Microdevices 16, 617 (2014).

30. B. Dorin, P. Parkinson, and P. Scully, J. Mater. Chem. C 5, 4923 (2017).

31. F. Klein, B. Richter, T. Striebel, C. M. Franz, G. v. Freymann, M. Wegener, and M. Bastmeyer, Adv. Mater. 23, 1341 (2011).

32. B. Richter, V. Hahn, S. Bertels, T. K. Claus, M. Wegener, G. Delaittre, C. Barner-Kowollik, and M. Bastmeyer, Adv. Mater. 29 (2017).

33. G. Vizsnyiczai, T. Lestyán, J. Joniova, B. L. Aekbote, A. Strejckova, P. Ormos, P. Miskovsky, L. Kelemen, and G. Bánó, Langmuir. 31, 10087 (2015).

34. C. Zhang, S. Jiang, Y. Huo, A. Liu, S. Xu, X. Liu, Z. Sun, Y. Xu, Z. Li, and B. Man, Opt. Express 23, 24811 (2015).

35. C. Li, A. Liu, C. Zhang, M. Wang, Z. Li, S. Xu, S. Jiang, J. Yu, C. Yang, and B. Man, Opt. Express 25, 20631 (2017).

36. C. Zhang, C. Li, J. Yu, S. Jiang, S. Xu, C. Yang, Y. J. Liu, X. Gao, A. Liu, and B. Man, Sensors Actuators B: Chem. 258, 163 (2018).

37. Z. Li, S. Jiang, Y. Huo, T. Ning, A. Liu, C. Zhang, Y. He, M. Wang, C. Li, and B. Man, Nanoscale. 10, 5897 (2018).

38. F. De Angelis, C. Liberale, M. Coluccio, G. Cojoc, and E. Di Fabrizio, Nanoscale. 3, 2689 (2011).

39. S. Hardt and F. Schönfeld, Microfluidic technologies for miniaturized analysis systems (Springer Science \& Business Media, 2007).

40. P. P. Patra, R. Chikkaraddy, R. P. Tripathi, A. Dasgupta, and G. P. Kumar, Nat. Commun. 5, 4357 (2014).

41. M. Rabe, D. Verdes, and S. Seeger, Adv. colloid interface science 162, 87 (2011). 


\section{FULL REFERENCES}

1. P. H. Jones, O. M. Maragò, and G. Volpe, Optical tweezers: Principles and applications (Cambridge University Press, Cambridge, 2015).

2. P. Polimeno, A. Magazzù, M. A. latì, F. Patti, R. Saija, C. Degli Esposti Boschi, M. G. Donato, P. G. Gucciardi, P. H. Jones, G. Volpe, and O. M. Maragò, "Optical tweezers and their applications," J. Quant. Spectrosc. \& Radiat. Transf. 218, 131-150 (2018).

3. A. Ashkin, "Acceleration and trapping of particles by radiation pressure," Phys. Rev. Lett. 24, 156 (1970).

4. P. C. Chaumet and M. Nieto-Vesperinas, "Time-averaged total force on a dipolar sphere in an electromagnetic field," Opt. Lett. 25, 1065-1067 (2000).

5. A. Ashkin, J. Dziedzic, J. Bjorkholm, and S. Chu, "Observation of a single-beam gradient optical trap for dielectric particles," Opt. Lett. 11, 288 (1986).

6. O. M. Maragò, P. H. Jones, P. G. Gucciardi, G. Volpe, and A. C. Ferrari, "Optical trapping and manipulation of nanostructures," Nat. Nanotechnol. 8, 807-819 (2013).

7. K. Svoboda and S. M. Block, "Optical trapping of metallic Rayleigh particles," Opt. Lett. 19, 930-932 (1994).

8. E. Messina, E. Cavallaro, A. Cacciola, M. A. latì, P. G. Gucciardi, F. Borghese, P. Denti, R. Saija, G. Compagnini, M. Meneghetti, V. Amendola, and O. M. Maragò, "Plasmon-enhanced optical trapping of gold nanoaggregates with selected optical properties," ACS Nano 5 , 905-913 (2011).

9. A. S. Urban, S. Carretero-Palacios, A. A. Lutich, T. Lohmüller, J. Feldmann, and F. Jäckel, "Optical trapping and manipulation of plasmonic nanoparticles: fundamentals, applications, and perspectives," Nanoscale 6, 4458-4474 (2014)

10. O. Brzobohatỳ, M. Šiler, J. Trojek, L. Chvátal, V. Karásek, A. Paták, Z. Pokorná, F. Mika, and P. Zemánek, "Three-dimensional optical trapping of a plasmonic nanoparticle using low numerical aperture optical tweezers," Sci. Reports 5, 8106 (2015).

11. O. Brzobohatỳ, M. Šiler, J. Trojek, L. Chvátal, V. Karásek, and P. Zemánek, "Non-spherical gold nanoparticles trapped in optical tweezers: shape matters," Opt. express 23, 8179-8189 (2015).

12. V. Amendola, R. Pilot, M. Frasconi, O. M. Marago, and M. A. lati, "Surface plasmon resonance in gold nanoparticles: a review," J. Physics: Condens. Matter 29, 203002 (2017).

13. D. Spadaro, M. A. latì, M. G. Donato, P. G. Gucciardi, R. Saija, A. R. Cherlakola, S. Scaramuzza, V. Amendola, and O. M. Maragò, "Scaling of optical forces on au-peg core-shell nanoparticles," RSC Adv. 5, 93139-93146 (2015).

14. D. Spadaro, M. A. latì, J. Perez-Pineiro, C. Vázquez-Vázquez, M. A. Correa-Duarte, M. G. Donato, P. G. Gucciardi, R. Saija, G. Strangi, and O. M. Marago, "Optical trapping of plasmonic mesocapsules: Enhanced optical forces and SERS," J. Phys. Chem. C pp. 691-700 (2017).

15. M. G. Donato, S. Vasi, R. Sayed, P. H. Jones, F. Bonaccorso, A. C. Ferrari, P. G. Gucciardi, and O. M. Maragò, "Optical trapping of nanotubes with cylindrical vector beams," Opt. Lett. 37, 3381-3383 (2012).

16. S. Skelton, M. Sergides, R. Patel, E. Karczewska, O. Maragó, and P. Jones, "Evanescent wave optical trapping and transport of micro-and nanoparticles on tapered optical fibers," J. Quant. Spectrosc. Radiat. Transf. 113, 2512-2520 (2012).

17. E. Messina, M. G. Donato, M. Zimbone, R. Saija, M. A. latì, L. Calcagno, M. E. Fragala, G. Compagnini, C. D’Andrea, A. Foti, P. G. Gucciardi, and O. M. Maragò, "Optical trapping of silver nanoplatelets," Opt. Express 23, 8720-8730 (2015).

18. A. Irrera, A. Magazzu', P. Artoni, S. H. Simpson, S. Hanna, P. H. Jones, F. Priolo, P. G. Gucciardi, and O. M. Marago, "Photonic torque microscopy of the nonconservative force field for optically trapped silicon nanowires," Nano Lett. 16, 4181-4188 (2016).

19. M. J. Guffey and N. F. Scherer, "All-optical patterning of au nanoparticles on surfaces using optical traps," Nano Lett. 10, 4302-4308 (2010).

20. S. Nedev, A. S. Urban, A. A. Lutich, and J. Feldmann, "Optical force stamping lithography," Nano Lett. 11, 5066-5070 (2011).

21. J. Gargiulo, I. L. Violi, S. Cerrota, L. Chvatal, E. Cortes, E. M. Perassi, F. Diaz, P. Zemanek, and F. D. Stefani, "Accuracy and mechanistic details of optical printing of single au and ag nanoparticles," ACS nano 11, 9678-9688 (2017)

22. M. G. Donato, E. Messina, A. Foti, T. Smart, P. Jones, M. A. latì, R. Saija, P. G. Gucciardi, and O. M. Maragò, "Optical trapping and optical force positioning of two-dimensional materials," Nanoscale $\mathbf{1 0}$ 1245-1255 (2018)

23. B. Fazio, C. D'Andrea, A. Foti, E. Messina, A. Irrera, M. G. Donato, V. Villari, N. Micali, O. M. Maragò, and P. G. Gucciardi, "Sers detection of biomolecules at physiological ph via aggregation of gold nanorods mediated by optical forces and plasmonic heating," Sci. Rep. 6, 26952 (2016)

24. A. Foti, C. D'Andrea, V. Villari, N. Micali, M. G. Donato, B. Fazio, O. M. Maragò, R. Gillibert, M. Lamy de la Chapelle, and P. G. Gucciardi, "Optical aggregation of gold nanoparticles for sers detection of proteins and toxins in liquid environment: towards ultrasensitive and selective detection," Materials. 11, 440 (2018).

25. H.-B. Sun and S. Kawata, "Two-photon photopolymerization and 3d lithographic microfabrication,” Adv. Polym. Sci. 170, 169-274 (2004).

26. C. Liberale, G. Cojoc, P. Candeloro, G. Das, F. Gentile, F. De Angelis, and E. Di Fabrizio, "Micro-optics fabrication on top of optical fibers using two-photon lithography," IEEE Photonics Technol. Lett. 22, 474-476 (2010).

27. C. Liberale, G. Cojoc, F. Bragheri, P. Minzioni, G. Perozziello, R. La Rocca, L. Ferrara, V. Rajamanickam, E. Di Fabrizio, and I. Cristiani, "Integrated microfluidic device for single-cell trapping and spectroscopy," Sci. Reports 3, 1258 (2013).

28. G. Nelson, R. Kirian, U. Weierstall, N. Zatsepin, T. Faragó, T. Baumbach, F. Wilde, F. Niesler, B. Zimmer, I. Ishigami, M. Hikita, S. Bajt, S.-R. Yeh, D. Rousseau, H. Chapman, J. Spence, and M. Heymann, "Three-dimensional-printed gas dynamic virtual nozzles for x-ray laser sample delivery," Opt. Express 24, 11515-11530 (2016).

29. S. Hengsbach and A. D. Lantada, "Rapid prototyping of multi-scale biomedical microdevices by combining additive manufacturing technologies," Biomed. Microdevices 16, 617-627 (2014).

30. B. Dorin, P. Parkinson, and P. Scully, "Direct laser write process for $3 d$ conductive carbon circuits in polyimide," J. Mater. Chem. C 5, 49234930 (2017)

31. F. Klein, B. Richter, T. Striebel, C. M. Franz, G. v. Freymann, M. Wegener, and M. Bastmeyer, "Two-component polymer scaffolds for controlled three-dimensional cell culture," Adv. Mater. 23, 1341-1345 (2011).

32. B. Richter, V. Hahn, S. Bertels, T. K. Claus, M. Wegener, G. Delaittre, C. Barner-Kowollik, and M. Bastmeyer, "Guiding cell attachment in $3 \mathrm{~d}$ microscaffolds selectively functionalized with two distinct adhesion proteins," Adv. Mater. 29 (2017).

33. G. Vizsnyiczai, T. Lestyán, J. Joniova, B. L. Aekbote, A. Strejckova, P. Ormos, P. Miskovsky, L. Kelemen, and G. Bánó, "Optically trapped surface-enhanced raman probes prepared by silver photoreduction to 3d microstructures," Langmuir. 31, 10087-10093 (2015).

34. C. Zhang, S. Jiang, Y. Huo, A. Liu, S. Xu, X. Liu, Z. Sun, Y. Xu, Z. Li, and $B$. Man, "Sers detection of $r 6 \mathrm{~g}$ based on a novel graphene oxide/silver nanoparticles/silicon pyramid arrays structure," Opt. Express 23, 24811-24821 (2015).

35. C. Li, A. Liu, C. Zhang, M. Wang, Z. Li, S. Xu, S. Jiang, J. Yu, C. Yang, and B. Man, "Ag gyrus-nanostructure supported on graphene/au film with nanometer gap for ideal surface enhanced raman scattering," Opt. Express 25, 20631-20641 (2017).

36. C. Zhang, C. Li, J. Yu, S. Jiang, S. Xu, C. Yang, Y. J. Liu, X. Gao, A. Liu, and B. Man, "Sers activated platform with three-dimensional hot spots and tunable nanometer gap," Sensors Actuators B: Chem. 258, 163-171 (2018).

37. Z. Li, S. Jiang, Y. Huo, T. Ning, A. Liu, C. Zhang, Y. He, M. Wang, C. $\mathrm{Li}$, and B. Man, "3d silver nanoparticles with multilayer graphene oxide as a spacer for surface enhanced raman spectroscopy analysis," Nanoscale. 10, 5897-5905 (2018)

38. F. De Angelis, C. Liberale, M. Coluccio, G. Cojoc, and E. Di Fabrizio, "Emerging fabrication techniques for $3 \mathrm{~d}$ nano-structuring in plasmonics and single molecule studies," Nanoscale. 3, 2689-2696 (2011). 
39. S. Hardt and F. Schönfeld, Microfluidic technologies for miniaturized analysis systems (Springer Science \& Business Media, 2007).

40. P. P. Patra, R. Chikkaraddy, R. P. Tripathi, A. Dasgupta, and G. P. Kumar, "Plasmofluidic single-molecule surface-enhanced raman scattering from dynamic assembly of plasmonic nanoparticles," Nat. Commun. 5, 4357 (2014).

41. M. Rabe, D. Verdes, and S. Seeger, "Understanding protein adsorption phenomena at solid surfaces," Adv. colloid interface science 162, 87106 (2011). 